\title{
Presence of Risk Factors and Co-Factors for Acquiring HPV Infection or Cervical Cancer in Women Living in a Rural Area and an Urban
}

\author{
Terán-Figueroa Yolanda1, Canúas-Landero Víctor Gabriel², Ramírez-Flores Élfego³, \\ Hernández-Madrigal Mónica ${ }^{3}$, Gallegos-García Verónica ${ }^{1}$, \\ Gutiérrez-Enríquez Sandra Olimpia ${ }^{*}$ \\ ${ }^{1}$ Nursing Faculty, Autonomic University of San Luis Potosí, San Luis Potosí, México \\ ${ }^{2}$ Faculty of Chemistry, Autonomous University Meritorious of Puebla, Puebla de Zaragoza, México \\ ${ }^{3}$ Faculty of Accounting and Administration, Autonomic University of San Luis Potosí, San Luis Potosí, México \\ Email: ${ }^{\text {sgutierr@uaslp.mx }}$
}

Received 23 December 2013; revised 27 January 2014; accepted 4 February 2014

Copyright (C) 2014 by authors and Scientific Research Publishing Inc.

This work is licensed under the Creative Commons Attribution International License (CC BY). http://creativecommons.org/licenses/by/4.0/

(c) (7) Open Access

\section{Abstract}

Objective: Identify the presence of some risk factors and co-factors for acquiring HPV (human papilloma virus) or cervical cancer in women from a rural area and an urban area. Material and Methods: Cross-sectional study conducted in 2008 in the State of San Luis Potosí, México. Sampling of non-probabilistic convenience was applied. 99 women participated $(73$ from urban area and 26 rural). Two surveys were used to identify risk factors and socio-demographic data. All women underwent HPV testing; the samples were self-collected and processed by the Hybrid Capture II method $^{\circledR}$. To analyze the data, descriptive and inferential statistics were applied. Results: The predominant age range was 37 to 42 years. $38.5 \%$ is in a rural community and an urban $37.3 \%$. $72.6 \%$ began their sexual life at 19 years or more in urban areas and $57.6 \%$ before 18 in rural areas. In relation to the number of sexual partners reported having had only one, $73.1 \%$ and $67.1 \%$ in rural and urban area respectively. Risk factors that were associated with HPV infection were the beginning of sexual activity at age 18 and under $(p=0.041)$ and the number of sexual partners $(p=0.001)$. Conclusions: There are more risk factors in women in urban areas but in rural areas it had the highest percentage of positive cases for infection by high-risk HPV.

\section{Keywords}

Cervical Cancer; Risk Factors; HPV

\footnotetext{
${ }^{*}$ Corresponding author.
} 


\section{Introduction}

One of the most important discoveries in the etiological research of the past 25 years, cancer has been the demonstration that cervical cancer is caused by Human Papilloma virus (HPV). Scientific evidence accumulated from virological, molecular, clinical and epidemiological studies has demonstrated that the Cervical Cancer (CC) is actually a sequel to long-term persistent infection by certain genotypes of HPV, primarily a virus from sexual transmission. The CC is the end result of a venereal disease unresolved [1]. HPV types are classified in mucosal and cutaneous. The mucosal group cataloged in two groups based on their ability to oncogenic genital level or cervical: low-risk (HR-HPV), warts producers, and high risk (HR-HPV), producing severe and invasive precancerous and cancerous lesions [2].

It is described that HR-HPV is necessary but not a sufficient cause for the development of CC. Risk factors and co-factors have been studied for acquiring HPV infection and progression of pre-neoplastic lesions neoplastic. So the risk factors reported are: initiation sex life (ISL) before age 18 [3] [4], have or have had multiple sex partners (including occasional) [4], that a sex partner has or had multiple sexual partners [5], frequenting women engaged in commercial sex, not using a condom [6] have not done circumcision [5], have never been conducted Papanicolaou (Pap) [5] and women living in poverty and exclusion [3] [5]. Furthermore, the co-factors are classified as: 1) persistence and progression [the causal agent (HPV) genotyping, variants, viral load, integration, co-infection with other HPV types, intrinsic to the woman (genetic) and IGF (peptide hormone that has anti-apoptotic activity and mutagenic) and individuals with reduced DNA repair their altered capacity, intrinsic to women (non-genetic) and high parity (more than 2 births) and coupled with high parity, IVS before age 18, and extrinsic as smoking, hormonal contraceptive use, diet low in antioxidants and co-infection with human immunodeficiency virus (HIV), herpes HSV-2 virus or Chlamydia trachomatis] and 2) invasion (It has been described that the expression of angiogenic factors such as VEGF and ANG to move from a pre-neoplastic lesion to CC is needed, however no specific data is available, and candidate genes as encouraging the viral invasion in the CC were described 23) [5]-[7].

In 2009, the disease was the second most common cancer in women worldwide with $88 \%$ of deaths in developing countries. In México, the CC representd a serious public health problem because of its high morbidity and mortality in the young [8] [9] women. In this country, it has been reported prevalence by age as follows: under 25 years approximately 15\%, 25 - 34 years and 35 - 44 years, approximately $8 \%, 45$ - 54 years $11 \%$, over 55 years $17 \%$ [9]. Lazcano Ponce et al. in 2001 described in the Mexican population a prevalence of $16.7 \%$ of HPV in women under 25 years of age. It decreased to $3.7 \%$ in women aged 25 - 44 years and increased again to $23.0 \%$ in those older than 65 years [10]. The INEGI reported in 2007, in our country a mortality rate of 14.2 per 100, 000 women and specifically in the state of San Luis Potosí was between 17 and 17.5, well above the national average [was recorded [11]. It had been reported that deaths from CC occurring in México each year mainly affected women living in marginalized areas and were attributed to the inequity in attention to sexual and that reproductive health was sociologically determined [12]. The higher mortality was concentrated in states where there were municipalities with high and very high marginalization.

In the present study, the presence of some risk factors and co-factors are identified for acquiring HPV infection or cervical cancer in women from two different populations, one rural and one urban, in order to assess whether the disadvantages described by marginalization are determinants for the pre-neoplastic lesions or CC present.

\section{Patients and Methods}

\subsection{Data Source}

Cross-sectional study conducted in 2008. The non-probability sampling was by convenience and involved 99 women (73 of 26 urban and rural areas). It was carried out in an urban area of the capital and in a rural area of San Luis Potosí México. The information was obtained from the use of two surveys, one designed by the National Institute of Public Health of México (INSP) to analyze the risk factors and other developed for this study to identify the socio-demographic data which was validated through obtaining a Cronbach alpha value of 0.90 .

\subsection{Materials}

All participants underwent the test for HR-HPV by Hybrid Capture ${ }^{\circledR}$ (Digene Corporation, 2007) processed by the Hybrid Capture II method and software v.2.0 at the National Institute of Public Health of México. The sam- 
ples were self-collected by the patients according to the protocol established by the INSP manual.

\subsection{Data Analysis}

The data processing was performed using the SPSS software v. 19.0 and Excel. To analyze the data measures of central tendency and dispersion were applied, likewise also used the Student $t$ test.

\subsection{Ethical Considerations}

All participants signed informed consent letter. At all times the laws were considered on Bioethics pointing Health Act [13] as well as the declaration of Helsinki [14]. The protocol was reviewed and accepted by the H. Committee on Research Ethics of the Faculty of Nursing UASLP key 0028HCEI-ENF09.

\section{Results}

The age range of the participating women was 19 to 67 . The highest percentage was found between 37 to 42 years in both populations. In relation to risk factors and co-factors studied it was found that in rural area the highest percentage started their sexual life before age 18 (57.6 \%), while in urban area $72.6 \%$ began their sexual life at 19 years or more. In relation to the number of sexual partners was found that the $73.1 \%$ of rural area and $67.1 \%$ of urban area having had only one. $43.8 \%$ of the urban area and $38.4 \%$ of rural area made their Pap more than 13 months ago. In relation to the use of hormonal contraceptives found that $80.7 \%$ and $71.7 \%$ of rural and urban areas respectively not having used them. $76.9 \%$ of rural area and $49.3 \%$ of urban area report having had more than one child. $53.8 \%$ of rural area and $54.7 \%$ of urban area mentioned not to smoke. $82.1 \%$ of urban area and $73.1 \%$ of rural area mentioned not having a sexually transmitted infection (STI). 96.1\% of women living in rural area and $98.6 \%$ of urban area mentioned ingest antioxidants in your diet.

When applying the statistical $t$ test for independent samples was observed that only two variables were statistically significant: the first intercourse $(p=0.041)$ among women aged 18 years or less and history in the number of sexual partnwers ( $\mathrm{p}=0.001)$ among women who have had up to 3 sexual partners. Other risk factors and co-factors were not statistically significant (Table 1). It should be noted that the prevalence of HR-HPV infection was $10.1 \%$ in both populations.

We also found that women in the urban area with a positive test for HR-HPV infection was started sex before age 18 in $12.5 \%$ and only $5.7 \%$ started their sexual life after 18 . The positive for HR-HPV infection with a higher percentage in rural areas were women who started their sexual life after 18 years (18.2\%) compared with those that became sexually active at age 18 or earlier (13.4\%) (Table 2).

It was observed that $33.3 \%$ of positive cases for HR-HPV infection among women living in urban areas had had 2 or more sexual partners. In this study, women who have had 5 or more sexual partners were found. When the same variables were analyzed in women in rural areas, a lower percentage was found in the positive for HR-HPV infection and who had two or more sexual partners (25\%). It should be noted that a large majority of patients with positive viral infection reported having had only one sexual partner (66.7\% in urban areas and 75\% in rural areas) (Table 3).

Furthermore, it was observed that of the 10 test positive for HR-HPV women, only 8 had been made before the Pap, and of these, 2 patients did not remember which the date of your last Pap smear was. The minimum reported as Pap last date was 6.3 months and maximum 38 months (3.1 years), with an arithmetic mean of 21.8 months and a standard deviation of 16.25. In analyzing the 6 positive cases for HR-HPV and Pap, it is noted that five of them were from urban areas and only one rural area. However, the urban area had two participants performed the Pap six months ago, one 8 months ago and two 3 years, while in rural area the only positive for HR-HPV test woman had performed the Pap 3 years ago (Table 4). The total number of women in the sample mentioned never having had an abnormal Pap report. Women who never received the results of the Pap think "all is well".

\section{Discussion}

Lazcano Ponce et al. in 2001 reported that in México most dysplasias were diagnosed after age 20, cancer in situ was presented significantly between 30 - 39 years old and invasive carcinoma after 40 years [10]. In the present 
Table 1. Risk factors and co-factors: comparison between women living in a rural area and an urban area.

\begin{tabular}{|c|c|c|c|c|c|c|c|}
\hline \multirow[t]{2}{*}{ Risk factors } & & \multicolumn{2}{|c|}{$\begin{array}{c}\text { Urban } \\
\text { Area } \\
n=73\end{array}$} & \multicolumn{2}{|c|}{$\begin{array}{c}\text { Rural } \\
\text { Area } \\
n=26\end{array}$} & \multicolumn{2}{|c|}{$\begin{array}{c}\text { Total } \\
\text { Sample } \\
\text { n= } 99\end{array}$} \\
\hline & & $\%$ & Fx & $\%$ & Fx & $\%$ & $\mathrm{Fx}$ \\
\hline \multirow{3}{*}{ Age of first sexual intercourse } & 18 years or less & 21.9 & 16 & 57.6 & 15 & 31.3 & 31 \\
\hline & 19 years or more & 72.6 & 53 & 42.3 & 11 & 64.6 & 64 \\
\hline & not answer & 5.4 & 4 & 0 & 0 & 4.0 & 4 \\
\hline \multirow{2}{*}{ Number of sexual partners } & One & 67.1 & 49 & 73.1 & 19 & 67.7 & 67 \\
\hline & Two or more & 32.9 & 24 & 26.9 & 7 & 32.3 & 32 \\
\hline \multirow{3}{*}{ Last Pap } & 12 months or less & 30.1 & 22 & 26.9 & 7 & 29.2 & 29 \\
\hline & 13 months or more & 43.8 & 32 & 38.4 & 10 & 42.4 & 42 \\
\hline & not answer & 26.0 & 19 & 34.6 & 9 & 28.2 & 28 \\
\hline \multirow{3}{*}{ Use of hormonal contraceptives } & Yes & 28.3 & 19 & 15.3 & 4 & 23.2 & 23 \\
\hline & No & 71.7 & 48 & 80.7 & 21 & 69.6 & 69 \\
\hline & not answer & 8.2 & 6 & 3.8 & 1 & 7.0 & 7 \\
\hline \multirow{3}{*}{ Number of children } & One & 46.4 & 34 & 23.1 & 6 & 40.4 & 40 \\
\hline & more than one & 49.3 & 36 & 76.9 & 20 & 56.5 & 56 \\
\hline & not answer & 4.1 & 3 & 0.0 & 0 & 3.0 & 3 \\
\hline \multirow{3}{*}{ smoking } & Yes & 31.5 & 23 & 34.6 & 9 & 32.2 & 32 \\
\hline & No & 54.7 & 40 & 53.8 & 14 & 54.5 & 54 \\
\hline & not answer & 13.6 & 10 & 11.5 & 3 & 13.1 & 13 \\
\hline \multirow{3}{*}{ Co-infection with other STI } & Yes & 16.4 & 12 & 26.9 & 7 & 19.1 & 19 \\
\hline & No & 82.1 & 60 & 73.1 & 19 & 79.7 & 79 \\
\hline & not answer & 1.3 & 1 & 0.0 & 0 & 1.0 & 1 \\
\hline \multirow{2}{*}{ Consumption of natural antioxidants } & Yes & 98.6 & 72 & 96.1 & 25 & 98.0 & 97 \\
\hline & No & 1.4 & 1 & 3.8 & 1 & 2.0 & 2 \\
\hline \multirow{2}{*}{ HR-HPV infection } & Yes & 8.2 & 6 & 15.3 & 4 & 10.1 & 10 \\
\hline & No & 91.7 & 67 & 84.6 & 22 & 89.8 & 89 \\
\hline
\end{tabular}

Table 2. Age for initiation sex life (ISL) and the result of HPV testing of women in urban and rural areas.

\begin{tabular}{|c|c|c|c|c|c|c|c|c|c|c|}
\hline \multirow{3}{*}{ Results of the HPV test } & \multirow{2}{*}{\multicolumn{2}{|c|}{$\begin{array}{c}\text { Urban Area } \\
\text { ISL before } 18\end{array}$}} & \multirow{2}{*}{\multicolumn{2}{|c|}{$\begin{array}{c}n=73 \\
\text { ISL after } 18\end{array}$}} & \multirow{3}{*}{ Total } & \multirow{2}{*}{\multicolumn{2}{|c|}{$\begin{array}{c}\text { Rural Area } \\
\text { ISL before } 18\end{array}$}} & \multirow{2}{*}{\multicolumn{2}{|c|}{$\begin{array}{r}n=26 \\
\text { ISL after } 18\end{array}$}} & \multirow{3}{*}{ Total } \\
\hline & & & & & & & & & & \\
\hline & Fx & $\%$ & Fx & $\%$ & & $\mathrm{Fx}$ & $\%$ & $\mathrm{Fx}$ & $\%$ & \\
\hline \multirow{2}{*}{$\begin{array}{l}\text { Negative } \\
\text { Positive }\end{array}$} & 14 & 87.5 & 50 & 94.3 & 64 & 13 & 86.6 & 9 & 81.8 & 22 \\
\hline & 2 & 12.5 & 3 & 5.7 & 5 & 2 & 13.4 & 2 & 18.2 & 4 \\
\hline Total & 16 & 100.0 & 53 & 100.0 & 69 & 15 & 100.0 & 11 & 100.0 & 26 \\
\hline
\end{tabular}


Table 3. Comparison between the number of sexual partners and the results of HPV testing among women in urban and rural areas.

\begin{tabular}{|c|c|c|c|c|c|c|c|c|c|c|}
\hline \multirow{4}{*}{ sexual partners } & \multicolumn{5}{|c|}{ Urban Area } & \multicolumn{5}{|c|}{ Rural Area } \\
\hline & \multicolumn{4}{|c|}{ VPH-AR Test } & \multirow{3}{*}{ Total } & \multicolumn{4}{|c|}{ VPH-AR Test } & \multirow{3}{*}{ Tota } \\
\hline & \multicolumn{2}{|c|}{ Negative } & \multicolumn{2}{|c|}{ Positive } & & \multicolumn{2}{|c|}{ Negative } & \multicolumn{2}{|c|}{ Positive } & \\
\hline & Fx & $\%$ & Fx & $\%$ & & Fx & $\%$ & Fx & $\%$ & \\
\hline \multirow{2}{*}{$\begin{array}{c}\text { One } \\
\text { Two or more }\end{array}$} & 45 & 68.2 & 4 & 66.7 & 49 & 16 & 72.7 & 3 & 75.0 & 19 \\
\hline & 22 & 31.8 & 2 & 33.3 & 24 & 6 & 27.3 & 1 & 25.0 & 7 \\
\hline Total & 67 & 100.0 & 6 & 100.0 & 73 & 22 & 100.0 & 4 & 100.0 & 26 \\
\hline
\end{tabular}

Table 4. HPV testing and time since completion of last Pap among women living in rural and urban areas with positive VPH-AR Test.

\begin{tabular}{|c|c|c|c|c|}
\hline \multirow[t]{2}{*}{ Área } & \multicolumn{2}{|c|}{ Test positive HR-HPV } & \multicolumn{2}{|c|}{ Time from performing the last Pap } \\
\hline & $\mathrm{Fx}$ & $\%$ & Fx & Months \\
\hline \multirow[t]{2}{*}{ Rural } & $1^{*}$ & 16.6 & 1 & 36 \\
\hline & & & 2 & 6 \\
\hline \multirow[t]{2}{*}{ Urban } & 5 & 83.3 & 1 & 8 \\
\hline & & & 2 & 36 \\
\hline Total & 6 & 100.0 & 6 & 86 \\
\hline
\end{tabular}

*Note: Three patients were not performed Pap in the rural area.

study, we found that most of the participating women had the age reported as a risk for developing pre-neoplasic lesions and CC, but generally no major differences were found in both populations.

It was extremely important to note that the prevalence of HR-HPV infection was $10.1 \%$, very similar to that found in other studies and other states of the Mexican Republic. In asymptomatic women in the general population, the prevalence of HPV infection was adjusted from $10.4 \%$ with considerable regional variability [12]. In developing countries, the prevalence of women aged 35 - 44 years was approximately 13\%. Specifically for México, A prevalence estimated by age had been reported as follows: fewer than 25\%, 15\%, 25 - 34 years, 8\% 35 - 44 years, $8 \% 45$ - 54 years, $11 \%$ and over 55 years, $17 \%$ [9].

Regarding risk factors and co-factors, León-Cruz in 2005 reported that there was a direct relationship between younger age at first sexual intercourse and increased risk of HPV as the number of sexual partners. This was merely a reflection of the likelihood of exposure to the virus and increased the frequency of the disease [15], which was related to the results presented here. However, it was identified that there were a number of factors and co-factors that were widely described in the scientific literature and were not statistically significant in this study. Perhaps, there should be other aspects that were influencing these populations, for example, the sexual habits of the husbands or partners (number of sexual partners that this has or, to make use of commercial sex), because high percentages of positive cases of infection with HR-HPV had been found in the rural area. But a relationship with the factors and co-factors traditionally studied were not found.

However, there were several works such as Poveda Torres et al. [16] where it was mentioned that the CC incidence and mortality were related to poverty, limited access to services, life in rural areas and low levels of education as well as different cultural patterns and the lack of communication and cooperation with epidemiological studies to establish a better progress in controlling this disease. Similarly, a study by Palacio Mejia et al. since 2003 found that the mortality was found related aspects in poverty as lack of education, unemployment, low socioeconomic status, residence in areas rural and lack of effective access to health services. In the same paper, the authors refer to women living in rural areas had 3.07 times higher risk of mortality from cancer compared with women living in urban areas in México. That was a problem of gender and equity. Therefore, it needed to be 
promoted elimination of regional disparities in the detection of CC [17].

Stage of this disease was bleak given the consequences and impact on the female population when you considered that a death was devastating to the integration of the society, when missing mother abandonment of children and often occurred disintegration of the family, which had implications for education and emotional health of the same, plus the catastrophic family spending to solve treatments with poor outcomes. Moreover, the expenditure of resources for health services was enormous and limited benefit. Now, the social substrate determined by poverty, gender inequality and poor access to information among other factors, kept large sections of the female population in conditions of high vulnerability and risk of disease and dying from it, of according to INEGI, in 2000 30.6\% of all women who died were illiterate, 21.9\% attended less than three years of elementary school and $13.8 \%$ only three to five years of the same level, indicating that $66.3 \%$ of the total deaths from this cause were illiterate women with incomplete elementary school [18].

The present study was found to be in rural areas where there were fewer women attending the Pap performed as a method of prevention, either by cultural issues because women did not have adequate information or resources and services necessary to monitor and control the disease. It is important to show that there are not significant differences between the two groups studied being observed, which raises the question whether in urban areas women are making use of the service, receiving health education or adequate information, and if really poverty and inequity in our day are factors that influence the disease presented in marginalized regions.

The results obtained in this study showed that of the 10 positive HPV test-AR women, only 8 had a Pap above, and 2 of these cases did not remember that it was the date of their last Pap smear, also most of these live in urban areas. It should be noted emphatically that a woman suffering CC reflected an enormous social inequality for four main reasons: 1) unequal access by the poor to health services women; 2) poor quality and poor infrastructure programs of prevention and control of CC in rural areas and areas with high poverty; 3) absence of primary prevention with HPV vaccination in young women due to inaccessible cost; 4) gender inequality, because for many years there was little attention and lack of gender perspective to offer an organized social response to confront this problem [19], but in the present study some results were not similar to the above statements and those reported in other studies, situations that are repeated in different investigations conducted by the group in San Luis Potosí state in México where indigenous settlements there . The reasons could be many, from effective health promotion in urban areas until adequate coverage within screening or an epidemiological transition and the presence of risk factors or cofactors own population. Regardless of all the above possibilities, it was very important to conduct a study population more widely court to understand the reasons for the differences.

\section{References}

[1] Castellsagué, P.X., de Sanjosé Llongueras, S. and Bosch, J.F.J. (2007) Epidemiology of HPV Infection and Cervical Cancer. New Prevention Options. In: Carreras, C.R., Xercavins, M.J. and Checa, V.M.A., Eds., Virus del Papiloma Human y Cáncer de Cuello de Útero, Editorial Médica Panamericana, Madrid, 14-17.

[2] Munoz, N., Bosch, F.X., de, S.S. and Shah, K.V. (1994) The Role of HPV in the Etiology of Cervical Cancer. Mutation Research, 305, 293-301. http://dx.doi.org/10.1016/0027-5107(94)90249-6

[3] Flores, Y.N., Bishai, D.M., Shah, K.V., Lazcano-Ponce, E., Lörincz, A., Hernández, M., et al. (2008) Risk Factors for Cervical Cancer among HPV Positive Women in México. Salud Pública de México, 50, 49-58. http://dx.doi.org/10.1590/S0036-36342008000100011

[4] Roura, E., Iftner, T., Vidart, J.A., Krüger, K.S., Bosch, F.X., Muñoz, N., et al. (2012) Predictors of Human Papillomavirus Infection in Women Undergoing Routine Cervical Cancers Screening in Spain: The CLEOPATRE Study. BMC Infectious Diseases, 12, 145-157. http://dx.doi.org/10.1186/1471-2334-12-145

[5] American Cancer Society (2013) Cervical Cancer: Early Detection and Prevention.

[6] Alliance for Cervical Cancer Prevention (2004) Cervical Cancer Prevention.

[7] Col-Legi Major, S.J. (2011) XXXI Course of Lower Genital Tract Pathology and Colposcopy. Barcelona.

[8] Mohar, A., Frías, M., Suchil, L., Mora-Macías, T. and De la Garza, J. (1997) Descriptive Epidemiology of Cancer in the National Cancer Institute of México. Salud Pública de México, 39, 253-258. http://dx.doi.org/10.1590/S0036-36341997000400002

[9] WHO/ICO Information Centre on HPV and Cervical Cancer (HPV Information Centre) (2010) Human Papillomavirus and Related Cancers in México. Summary Report. www.who.int/hpvcentre

[10] Lazcano-Ponce, E., Herrero, R., Muñoz, N., Curz, A., Shah, K., Alonso, P., et al. (2001) Epidemiology of HPV Infec- 
tion among Mexican Women with Normal Cervical Cytology. International Journal of Cancer, 91, 412-420. http://dx.doi.org/10.1002/1097-0215(20010201)91:3<412::AID-IJC1071>3.0.CO;2-M

[11] Federal Government of México (2009) National Institute of Statistics, Geography and Informatics (INEGI) México.

[12] Clifford, G.M., Gallus, S., Herrero, R., Muñoz, N., Snijders, P.J., Vacarella, S., et al. (2005) Wordwide Distribution of Human Papillomavirus Types in Cytologically Normal Women in the International Agency for Research on Cancer HPV Prevalence Surveys: A Pooled Analysis. Lancet, 366, 991-998. http://dx.doi.org/10.1016/S0140-6736(05)67069-9

[13] Federal Government of México (1983) Regulation of the General Law of Health Research Subject. www.censida.salud.gob.mx/descargas/etica/reglamento.pdf

[14] Declaration of Helsinki, Apéndice F. Finlandia (1964) http://www.inb.unam.mx/bioetica/documentos/declaracionhelsinki.pdf

[15] León Cruz, G. and Bosques Diego, O.D. (2005) Infection by the Human Papillomavirus and Factors Related to Sexual Activity in the Genesis of Cervical Cancer. Revista Cubana de Obstetricia y Ginecología, 31, 1-8.

[16] Torres Poveda, K.J., Arredondo López, A.A., Duarte Gómez, M.B. and Madrid Marina, V. (2008) Infection by the Human Papillomavirus and Factors Related to Sexual Activity in the Genesis of Cervical Cancer: Conceptual Models of Public Health. Health in Tabasco, 14, 807-815.

[17] Palacio-Mejía, L.S., Rangel-Gómez, G., Hernández-Avila, M. and Lazcano-Ponce, E. (2003) Cervical Cancer, a Disease of Poverty: Mortality Differences between Urban and Rural Areas in México. Salud Pública de México, 45, S315S325.

[18] Federal Government of México (2006) National Institute of Statistics, Geography and Informatics (INEGI) World Cancer Day, México.

[19] Panel of the Mexican Federation of Obstetrics and Gynecology. Consensus for the Prevention of Cervical Cancer in México (2011) La Carga del Cáncer Cervicouterino y de la Infección Por Virus del Papiloma Humano en México y en el Mundo. Ginecología y Obstetricia de México, 79, 788-793. 